\title{
Investigation of Mechanical Properties of MIG-Brazed TRIP 800 Steel Joints Using Different Working Angles
}

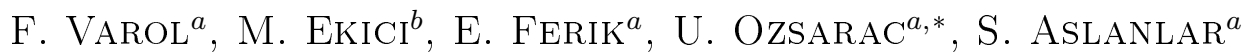 \\ ${ }^{a}$ Department of Metallurgical and Materials Engineering, Sakarya University, 54187 Sakarya, Turkey \\ ${ }^{b}$ Vocational School of Yalova, Yalova University, Yalova, Turkey
}

\begin{abstract}
In this study, TRIP 800 (Transformation Induced Plasticity) steel plates, $1.5 \mathrm{~mm}$ in thickness, were joined with copper-based $(\mathrm{CuAl})$ wire by the gas metal arc brazing technique. Specimens were prepared in butt joint form. Five different working angles $50^{\circ}, 60^{\circ}, 70^{\circ}, 80^{\circ}$ and $90^{\circ}$ were selected for brazing operations. A copper based CuAl8 wire was used as the filler metal. After the metal inert gas brazing process, butt joined specimens were exposed to tensile test in order to characterize the mechanical properties. The microstructure of the joints was investigated by scanning electron microscope (SEM) and optical microscope to see the joinability of TRIP 800 steel by gas metal arc brazing technique.
\end{abstract}

DOI: 10.12693/APhysPolA.127.965

PACS: $81.20 . \mathrm{Vj}, 81.70 . \mathrm{Bt}, 81.05 . \mathrm{Bx}$

\section{Introduction}

Transformation Induced Plasticity (TRIP)-aided multiphase steels are new generation of low-alloy steels that exhibit an enhanced combination of strength and ductility, thus satisfying the requirements of automotive industry for good formable high-strength steels [1]. Also TRIP steels have been shown to offer superior ductility and work hardening properties when compared to DP grades of the same strength. The microstructure consists of three primary phases: ferrite, bainite and retained austenite [2]. The retained austenite grains transform into martensite during deformation and this will delay the onset of necking, leading to higher ductility by means of the TRIP effect [3]. Galvanized TRIP steel sheets are widely used in construction with corrosion resistance and especially in automotive industry [4]. Metal inert gas (MIG) welding of zinc-coated thin plates in automotive industry leads to major issues, mainly zinc evaporation followed by a decrease in corrosion resistance, as well as residual strains and stresses, which is difficult to minimize [5]. To reduce the risk of zinc evaporation, new welding processes with a low heat supply have begun to gain ground, for example MIG-brazing, which combines the advantages of the MIG process (high deposition rate, high welding speed and adaptable to automation) and brazing (without any intense fusion of the welded parts and without any appreciable alteration of the mechanical properties of the base metal and the coating applied) [6]. Resistance spot welding is also used in automotive industry in joining of high quality steel sheets [7]. Varol et al. studied the MIG-brazing of dual phase (DP) steel sheets to investigate the effect of working angle on mechanical

${ }^{*}$ corresponding author; e-mail: ozsarac@sakarya.edu.tr properties [8]. MIG-brazing of galvanized steel sheets was studied using copper based filler and it is found that the joint strength is higher than that of the base materials [9-10]. Akkas et al. researched the shielding gas flow rate effect on tensile strength of MIG-brazed TRIP 800 steel [11]. In present paper, MIG-brazing of galvanized steels was emphasized on the microstructure and strengthening behavior and mechanisms of the joint.

\section{Material and method}

In this study, TRIP 800 steel was chosen for joining with MIG brazing technique. Steel plates of $1.5 \mathrm{~mm}$ thickness with $7.5 \mu \mathrm{m}$ zinc coating were used. The filler metal was a solid wire with a diameter of $1 \mathrm{~mm}$, classified as AWS ERCuAl8. MIG-brazing operations were performed with five different torch angles of $50^{\circ}, 60^{\circ}$, $70^{\circ}, 80^{\circ}$ and $90^{\circ}$ to detect the effect of angle parameter on tensile behavior of joint. MIG brazing operations were carried out in a current controlled MIG welding machine with a capacity of $300 \mathrm{~A}$. Argon was used as the shielding gas at a flow rate of 12 liters $/ \mathrm{min}$. The surface of the samples was cleaned by acetone before MIG-brazing. All MIG-brazed joints were prepared automatically with a welding machine and a torch speed control device.

\section{Experimental results and discussion}

Steel plates were joined by MIG brazing in butt joint form. In each form, different working angles were used and tensile tests were carried out. The results are given in the diagram below.

\subsection{Tensile test results}

In this study, the uniaxial tensile tests were applied according to ASTM E8 standard. The yield stress was measured as $510 \mathrm{MPa}$ for TRIP 800 steel before brazing process. The torch angle and maximum tensile stress 
were handled as two important parameters. The relationship of these parameters is given in Fig. 1. In butt joint specimens, the ultimate tensile stress $\left(\sigma_{U T S}\right)$ value of $855 \mathrm{MPa}$ was measured. Its value decreased to $820 \mathrm{MPa}$ for $60^{\circ}$. After that, the $\sigma_{U T S}$ increased up to $840 \mathrm{MPa}$ with increasing working angle. For $90^{\circ}$ angle, its value again decreased by $5 \mathrm{MPa}$ and measured $835 \mathrm{MPa}$. The tensile test was repeated three times for each torch angle. According to test results, $50^{\circ}$ torch angle, which gives the highest tensile strength value, can be recommended for joining of TRIP 800 steel sheets by using metal inert gas brazing method.

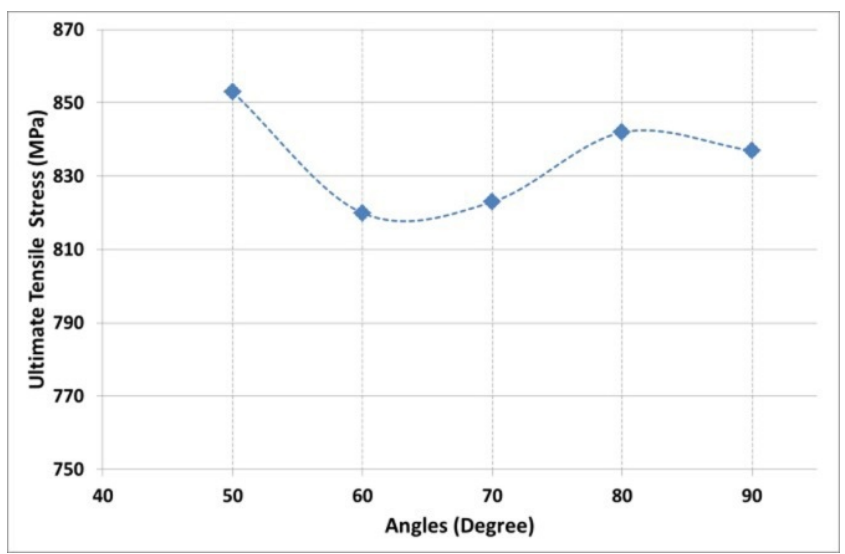

Fig. 1. Tensile test results.

\subsection{Microstructure}

In Figure 2, the microstructure of the specimens MIGbrazed at $80^{\circ}$ work angle are shown. Three different regions can be seen. In Fig. 2a brazing zone and heat affected zone (HAZ) are shown together. An interface region, separating them, can be easily seen. Atoms were spread from the base metal towards filler metal as a result of diffusion in the surface of contact surface between the brazed zone and the base metal. Additionally, in HAZ zone, the grain structure grew with the effect of heat and it became finer while going to the base metal. Figure $2 \mathrm{~b}$ shows the inside of brazing region. Due to directional solidification, the microstructure is fully dendritic, elongated dendrites are seen all around the brazing zone of the joint. In Fig. 2c, base metal of TRIP 800 steel is shown. During MIG-brazing of steel sheets, heat input makes grain size coarser and strength decreases. However, the excellent mechanical properties of TRIP steel mainly attribute to favorable hardenability, due to this great difference between yield strength and tensile strength (i.e. $510 \mathrm{MPa}$ and $855 \mathrm{MPa}$, respectively). The excessive heat input to the base metal is the second important factor affecting the ultimate tensile strength rise, seen in samples. These results show similarity with the study of Varol et al. [11].

Figure 3 shows the secondary electron image SEM microstructure of TRIP 800 steel and brazing zone MIG-

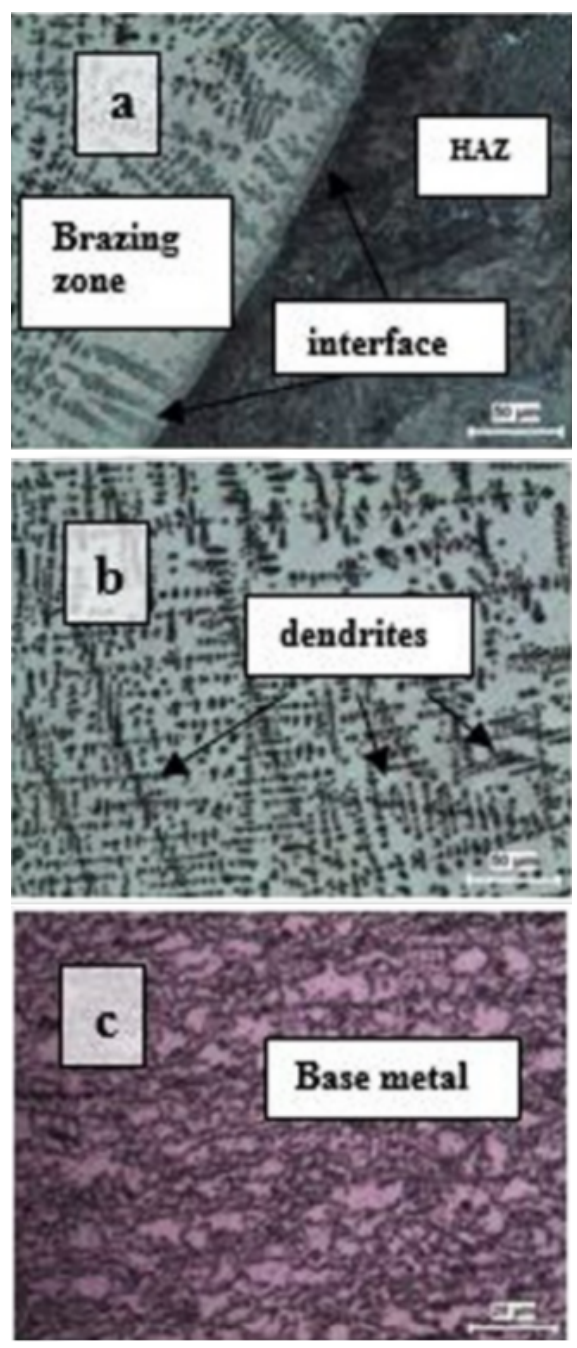

Fig. 2. MIG-Brazed TRIP 800 Microstructures, (a) interface, (b) braze, (c) base metal.

brazed at $80^{\circ}$ torch angle. As mentioned before, the dendrites have occurred in the brazing zone. There is an interface layer between the base metal and braze zone. This white, narrow layer is mainly composed of iron, copper and other alloying elements, present in the filler wire, as mentioned by Akkas et al. [12]. In addition, martensite needles can be easily detected in base metal region. However, not only martensite, but also ferrite and bainite phases occur the TRIP steel.

TABLE I

EDS analysis of the brazed joints (atomic wt.\%).

\begin{tabular}{cccccc}
\hline \hline Point & $\mathrm{Al}$ & $\mathrm{Si}$ & $\mathrm{Mn}$ & $\mathrm{Fe}$ & $\mathrm{Cu}$ \\
\hline 1 & 3.327 & 1.265 & 0.287 & 75.412 & 19.709 \\
2 & 7.320 & - & 0.545 & 63.745 & 28.390 \\
3 & 8.828 & - & 0.428 & 6.362 & 84.382 \\
\hline
\end{tabular}

In Fig. 4, copper-rich braze joint zone was investigated. The EDS analysis shows that dendrites in copper based matrix are mainly composed of iron, copper and other 


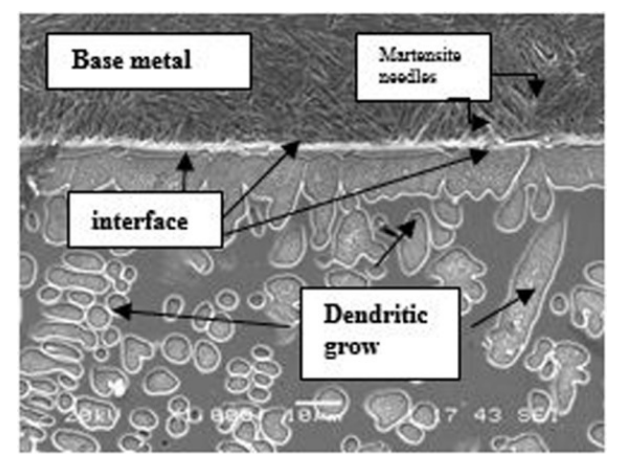

Fig. 3. SEM image of the brazed joints.

alloying elements presented in filler wire. EDS analysis of the brazed joint is presented in Table I. During the arc brazing process, it was observed that the number of dendrites had increased and grew into copper-rich brazing zone, as shown in Fig. 3. These dendrites were distributed throughout the joining zone.

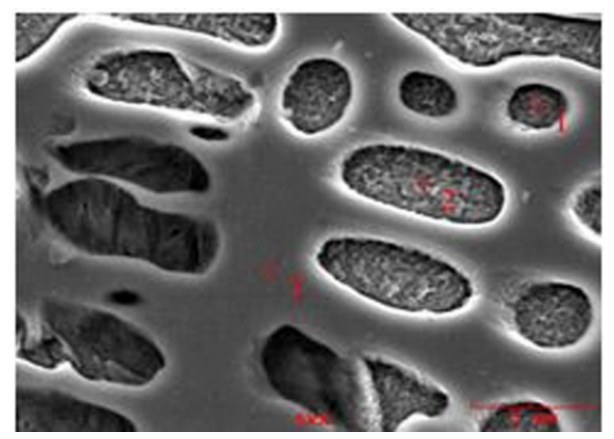

Fig. 4. SEM micrograph and EDS analysis of the joint brazed in $50^{\circ}$ torch angle.

\section{Conclusions}

The joinabinability of TRIP 800 steel with a copper based $\mathrm{CuAl} 8$ filler metal, by means of MIG brazing method, was examined and it was shown that very little or no melting has been occurred in the base metal region. In addition, the effect of MIG-brazing parameters on tensile properties of TRIP 800 steel sheet joints was investigated. The following conclusions were drawn:

- $50^{\circ}$ working angle seems to be the best torch angle, because the highest tensile strength $\left(\sigma_{U T S}\right)$ value of $855 \mathrm{MPa}$ was measured for this angle.
- The increase in iron diffusion brought the stretching of dendrite like branches into copper-rich joint zone. These dendrite branches mainly contain iron and copper. Additionally, increase of dendrites resulted in the increase in strength.

\section{Acknowledgments}

The authors wish to thank to Sakarya University Scientific Research Foundation (Project number: 2010-0506-008) for their support.

\section{References}

[1] I.D. Choi, ISIJ Int. 42, 1483 (2002).

[2] S. Oliver, T.B. Jones, G. Fourlaris, Mater. Characterization 58, 390 (2007).

[3] G.K. Tirumalasetty, M.A. Huis, C. Kwakernaak, J. Sietsma, W.G. Sloof, H.W. Zandbergen, Acta Materialia 60, 1311 (2012).

[4] AWS. Welding Processes, Welding Handbook, 2, 8th ed. Miami: AWS.

[5] L Quintino, G. Pimenta, D. Iordachescu, R.M. Miranda, N.V. Pépe, Mater. Manuf. Process. 21, 63 (2006).

[6] A.F. Rangel, L.A. Matlakhova, R.P.D.R. Paranhos, A.N. Malakhov, Weld. Int. 20, 889 (2006).

[7] N. Akkas, F. Varol, E. Ferik, E. Ilhan, U. Ozsarac, S. Aslanlar, Acta Phys. Pol. A. 125, 500 (2014).

[8] F. Varol, M. Colak, N. Akkas, U. Ozsarac, S. Aslanlar, Materialprufung 56, 858 (2014).

[9] R.F. Li, Z.S. Yu, K. Qi, T. Nonferr. Metal. Soc. 16 , 397 (2006).

[10] Z.S. Yu, Y.Y. Qian, R.F. Li, F.M. Zhou, Mater. Sci. Tech. 19, 1399 (2003).

[11] F. Varol, E. Ferik, U. Ozsarac, S. Aslanlar, Mater. Design 52, 1099 (2013).

[12] N. Akkas, F. Varol, E. Ferik, E. Ilhan, U. Ozsarac, S. Aslanlar, Acta Phys. Pol A. 125, 473 (2014). 